\section{Determination of occupational health and safety practices and the level of perception of safety culture from the perspective of housekeeping personnel in hospitals}

Hastanelerde kurum ev idaresi personeli perspektifinden iş sağlığı ve güvenliği uygulamalarının ve güvenlik kültürüne ilişkin alg1 düzeylerinin belirlenmesi $^{1}$

\author{
Birgül Çiçek ${ }^{2}$ \\ Sibel Erkal ${ }^{3}$
}

\begin{abstract}
This study was planned and conducted to determine the occupational health and safety practices and the level of perception of safety culture from the perspective of housekeeping personnel in hospitals. The population of the study consists of housekeeping personnel at 14 hospitals who accepted to participate in the study from all hospitals affiliated to the TR Ministry of Health and universities with more than 50 inpatient bed availability in Ankara city center apart from the hospitals specialized in certain fields, military hospitals and private hospitals within the boundaries of Ankara province. The proportional sampling method was used in the determination of the number of personnel to participate in the study from each hospital that agreed to participate in it and the study was carried out with 400 housekeeping personnel. A questionnaire form was prepared with 'Safety Culture Scale' and 'Employee Health and Safety Culture Scale' to collect the data in the study. The housekeeping personnel who have received education in the field of
\end{abstract}

Özet

$\mathrm{Bu}$ araştırma hastanelerde çalışan kurum ev idaresi personeli perspektifinden iş sağlığ ve güvenliği uygulamalarının ve güvenlik kültürüne ilisskin alg1 düzeylerinin belirlenmesi amaciyla planlanmış ve yürütülmüştür. Araştırmanın evrenini Ankara il sınırları içinde bulunan 50 yatak kapasitesinin üzerindeki tüm T.C. Sağlık Bakanlığı'na ve üniversitelere bağlı çalışmayı kabul eden hastaneler oluşturmaktadır. Araştırmanın örneklemini, çalışmaya katılmayı kabul eden hastanelerden 400 kurum ev idaresi personeli oluşturmaktadır. Veri toplamak amaciyla "Güvenlik Kültürü Ölçeği” ile "Çalışan Sağlığı ve Güvenliği Ölçeği” kullanılarak anket formu oluşturulmuştur. Kurum ev idaresi personelinin \% 10,3'ünün iş kazası geçirdiği belirlenmiştir. İş kazası geçiren personelin yarıdan biraz fazlası 'atıkları toplarken' kaza geçirmiş olup, geçirilen kaza tipleri arasında; 'kesici delici alet yaralanmalarr'n belirtenler ilk strada yer almaktadir. Kurum ev idaresi personelinin 'Güvenlik Kültürü' ile 'Çalsşan Sağllğ1 ve Güvenliği Kültürü’ne ilişkin alg1

\footnotetext{
${ }^{1}$ Bu çalışmada, 'Hastanelerde Kurum Ev İdaresi Personeli Perspektifinden İş Sağllı̆ı ve Güvenliği Uygulamalarının ve Güvenlik Kültürüne İlişkin Alg1 Düzeylerinin Belirlenmesi’ adlı Yüksek Lisans Tez çalışmasında elde edilen verilerden yararlanılmıştır ve ayrıca Hacettepe Üniversitesi Bilimsel Araştırma Projeleri Koordinasyon Birimi tarafından SYL-201610152 proje koduyla lisansüstü tez projesi olarak desteklenmiştir.

2 Arş. Gör. Uzm., Hacettepe Üniversitesi , İİ:B.F Aile ve Tüketici Bilimleri, birgulaydin@,hacettepe.edu.tr

3 Prof. Dr., Hacettepe Üniversitesi, İİ:B.F Aile ve Tüketici Bilimleri, serkal@,hacettepe.edu.tr
} 
Çiçek, B., \& Erkal, S. (2016). Hastanelerde kurum ev idaresi personeli perspektifinden iş sağllğı ve güvenliği uygulamalarının ve güvenlik kültürüne ilişkin alg1 düzeylerinin belirlenmesi. Journal of Human Sciences, 13(3), 4416-4431. doi:10.14687/jhs.v13i3.3993

"health and safety at work" comes first among the personnel almost all of which have received in-service training. It was identified that $10,3 \%$ of the personnel participating in the study had experienced occupational accidents. It was stated that $53,8 \%$ of the housekeeping personnel who had experienced occupational accidents had these accidents while 'collecting waste', when the types of the accidents experienced by those who had had occupational accidents were examined, it was concluded that while the personnel 'exposed to sharp object injuries' took the first place. While a statistically significant difference $(p<0,05)$ was found between the perception levels related to the 'Safety Culture' and 'Employee Health and Safety Culture' of the housekeeping personnel and the opinions of the personnel on the state of attaching importance to the applications related to health and safety at work by the hospital administration, the condition of receiving education on the use and maintenance of the equipment, accident protection and the use of cleaning products, there was no statistically significant difference $(p>0,05)$ between gender, age, total service period, education level, marital status, service period at the hospital of employment, the condition of experiencing occupational accidents at the hospital of employment, the reason of the accident experienced, general opinions related to the reasons of occupational accidents, cleaning methods, the condition of receiving education on infection control, sanitation and personal hygiene.

Keywords: Occupational health and safety; safety culture; housekeeping personnel; cleaning personnel; occupational accident.

(Extended English abstract is at the end of this document)

\section{GİRIŞ}

İnsan yaşamının büyük bir bölümü iş yerinde geçmektedir. Çalışma hayatında; fiziksel, kimyasal, biyolojik ve psiko-sosyal birçok etken bulunmakta dolayısıyla da kişinin sağlık, güvenlik ve verimliliği etkilenmektedir (Güven, 2006). Bu nedenle, çalışma hayatının insan sağlığı üzerinde önemli etkileri bulunmaktadır. Bu etkiler hem çalışanların sağlı̆̆ı hem de çevre ve toplum sağlığı bakımından da önem taşımaktadır. düzeyleri ile personelin hastane yönetiminin iş sağlığı ve güvenliği ile ilgili uygulamalarına önem verme durumuna ilişkin görüşleri, araç gereçlerin kullanımı ve bakımı, kazalardan korunma ve temizlik maddelerinin kullanımı konularına ilişkin eğitim alma durumu arasında istatistiksel olarak anlamlı farklilik $(p<0,05)$ bulunurken; cinsiyet, yaş, toplam hizmet yıll, öğrenim düzeyi, medeni durum, çalıştığı hastanedeki hizmet yılı, çalıștı̆̆1 hastanede iş kazası geçirme durumu, geçirilen iş kazasının nedeni, genel olarak iş kazalarının nedenine ilişkin görüşleri, temizlik yöntemleri, enfeksiyon kontrolü ve sanitasyon ile kişisel hijyenle ilgili eğitim alma durumları arasında istatistiksel olarak anlamlı farklilik ( $p>0,05)$ bulunmamıstır.

Anahtar Kelimeler: İş sağllğı ve güvenliği; güvenlik kültürü; kurum ev idaresi personeli; temizlik personeli; iş kazaları. 
Çiçek, B., \& Erkal, S. (2016). Hastanelerde kurum ev idaresi personeli perspektifinden iş sağllğ̆ ve güvenliği uygulamalarının ve güvenlik kültürüne ilişkin alg1 düzeylerinin belirlenmesi. Journal of Human Sciences, 13(3), 4416-4431. doi:10.14687/ihs.v13i3.3993

On altıncı ve on yedinci yüzyıllarda yaşanan bir takım sosyo-ekonomik olaylar ve gelişmeler çalışma yaşamında iş sağlığı ve güvenliğiyle ilgili konular açısından önemli etkiler yaratmıştır. Dünyada ve ülkemizde meydana gelen teknolojik gelişmeler ve özellikle sanayi devrimiyle birlikte çalışanlar için olumsuz koşullar oluşmuş, çalışanların iş sağllı̆̆1 ve güvenliğiyle ilgili sorunlar ortaya çıkmıştır (Bilir \& Yıldız, 2014; Uçkun, Yüksel, Demir \& Yüksel, 2013; Bostanc1, 2011).

Bir gereklilik olarak ortaya çıkan, özünde yaşama hakkının korunmasını içeren (Kılkış \& Demir, 2012) İş Sağllğ̆ ve Güvenliği (ISG) kavramı " işin yapılması sirasında işyerindeki firiki gevre koşullar nedeniyle iş̧ilerin maruz kaldıklar sağhle sorunlar ve mesleki risklerin ortadan kaldmlmast veya azaltılmasi" şeklinde tanımlanmıştır (Balkır, 2012: 58).

Uluslararası Çalışma Örgütü (ILO) ile Dünya Sağlık Örgütü (WHO) 1950 yllında İSG kavramını; "Her çeşit iște çalışan isçilerin, fiæilesel, rubsal ve sosyal yönden tam iyilik hallerinin sürdürülmesi ve geliștirilmesi; çalısma koşullarndan dolayn işsilerin sağhklarm yitirmelerinin önlenmesi; çalıs̆ma sirasinda, iş̧cilerin sağhklarm olumsuz yönde etkileyecek etmenlerden korunmalar; isscilerin fisyolojik ve psikolojik yapularna uygun işe yerleştirilmesi ve bunun sürdürülmesidir." şeklinde tanımlamışlardır (International Labour Conference, 2009). İş sağlı̆̆1 ve güvenliği çalışanların yaptıkları işi ve işyeriyle ilgili olarak işyeri dışındaki faaliyetlerini de kapsadığından geniş bir perspektiften bakmayı gerektiren bir konudur (Yüksel, 2003). Aynı zamanda, dinamik bir kavram olup, çalışanların sağlık ve güvenliğini kapsayan tüm durumlara, çalışma şartlarına, mevcut risk ve tehlikelere bağlı olarak sürekli değişim göstermektedir (Keleş, 2004: 16).

İş sağllğı ve güvenliği bilim dalı, yirminci yüzyılın başlarında tıp bilimlerini kapsarken; yüzyılın ikinci yarısında temel ve uygulamalı bilim dallarını kapsayarak multidisipliner bakış açısıyla, her işin kendi doğasına yönelik olarak farklı önlemlerin geliştirilmesini gerekli kılan teknik bir bilim dalı olarak bağımsızlaşmış (Uçkun, vd., 2013) ve disiplinler arası etkileşimi ve işbirliğini gerekli kılan, tıp, hukuk, fizik, psikoloji gibi pozitif ve sosyal bilimlerin katkılarıyla gelişen bir alan haline gelmiştir (Bilir \& Yıldız, 2014; Demirbilek \& Çakır, 2008).

Sanayi Devriminden sonra sosyal risk olarak değerlendirilen iş kazalarının yaşanmasına sosyal, ekonomik, psikolojik ve çevresel faktörler neden olmaktadır. İş güvenliğinin alt kavramı olan ve sanayileşme ile teknolojik gelişmelerin sonucunda çalışma yaşamındaki değişmelerle birlikte sıkça görülmeye başlanan (Camkurt, 2013) iş kazaları, WHO tarafindan, "önceden planlanmamıs, çŏ̆u zaman yaralanmalara, makine ve teçbizatın zarara uğramasina veya üretimin bir süre durmasina yol açan olay" şeklinde tanımlanırken; (Özkilıç, 2005: 8), ILO ise iş kazasını; "belirli bir zarar veya yaralanmaya yol açan, önceden planlanmamış beklenmedik olay" olarak tanımlamışır (ILO, 1998). Iss kazalarının temel nedenleri; insanın fizyolojik ve psikolojik durumundan kaynaklanan güvensiz davranışlar ve güvensiz çalışma ortamı olmak üzere iki sınıfa ayrılmaktadır. İş kazalarının ve meslek hastalıklarının 'önlenebilir' olduğundan yola çıkılarak hazırlanan 30.06.2012 tarihinde yürürlüğe giren 6331 Sayılı İş Sağlığ1 ve Güvenliği Kanunu (ISGK) işyerlerinde iş sağllı̆ı ve güvenliğinin sağlanması, mevcut sağlık ve güvenlik koşullarının iyileştirilmesi için işveren ve çalışanların görev, yetki, sorumluluk, hak ve yükümlülüklerini düzenlemektedir (İSGK, Md.1).

ISGK'da tarafların yükümlülüklerine bakıldığında işverene, çalışana ve devlete büyük sorumluluklar verildiği görülmektedir. Fakat buna rağmen, meydana gelen iş kazalanı ve iş kazalarının hem işletmeler hem de ülke ekonomisi açısından büyük zarar verdiği düşünülürse, iş kazalarının önlenmesi açısından ele alınacak en önemli konulardan birisi de işletmelerde güvenlik kültürü oluşturulmasıdır (Akalp \& Yamankaradeniz, 2013). İş kazalarının iki temel nedeninden biri olan güvenli olmayan çalışma ortamı, iş sağlı̆̆1 ve güvenliği konusunda önlemler alınarak giderilebilirken, güvensiz davranışlar, çalışan personelin eğitim alarak güvenli davranışları benimsemesiyle ve iş yerinde güvenlik kültürü oluşturulmasıyla azaltılabilir (Aktay, 2011: 1).

Gelişmekte olan ülkemizde de kalkınma anlayışının önemi gittikçe artmaktadır. Bir toplumun gelişmiş sayılabilmesi için ekonomik kalkınmanın yanı sıra insani gelişme kriterleri de 
Çiçek, B., \& Erkal, S. (2016). Hastanelerde kurum ev idaresi personeli perspektifinden iş sağllğı ve güvenliği uygulamalarının ve güvenlik kültürüne ilişkin alg1 düzeylerinin belirlenmesi. Journal of Human Sciences, 13(3), 4416-4431. doi:10.14687/jhs.v13i3.3993

önemlidir. Buna bağlı olarakta Türkiye ekonomisinde iş sağllğı ve güvenliği önemli bir kavram haline gelmiştir (Uçkun, vd., 2013).

Insan faktörü dikkate alınarak, son dönemlerde iş kazalarını önlemede öne çıan kavramlardan birisi de güvenlik kültürü kavramıdır. Örgüt kültürünün alt unsuru olan ve "bir örgütte çalışan herkesin davranışlarını yönlendiren; normlar, davranışlar, değerler, inançlar, alışkanlıklar ile bir örgütün güvenliğini iyileştirici yönde sahip olduğu yapılar, politikalar ve uygulamaları" içeren güvenlik kültürünün sağlanması ve geliştirilmesi, iş kazalarılyla mücadelede ilk olarak benimsenmesi gereken bir kavramdır (Aytaç, 2011). Aynı zamanda günümüzde çalışma ortamındaki tehlikelere ilişkin önlemlerin yetersiz olması nedeniyle hem çalışanlarda hem de işverenlerde güvenlik kültürü bilincinin ve önleme kültürünün oluşturulması bir zorunluluk haline gelmiştir (Kılkış \& Demir, 2012; Güven, 2006). Çalışanların sağlık durumlarının korunması ve daha da iyileştirilmesi için gösterilen çabalar ancak bu güvenlik bilincinin ve kültürünün oluşturulmasıyla sağlanabilir (Güven, 2006).

İş kazalarının ve meslek hastalıklarının 'önlenebilir' olmasından yola çıkılarak çalışma ortamında meydana gelebilecek risk ve tehlikelerin önlenmesi ve çalışanların sağlığının korunması amacıyla iş sağlığ1 ve güvenliği çalışmaları ile güvenlik kültürünün oluşturulması ve çalışanların bu bilinçle güvenli davranış sergilemesi iş sağlığı ve güvenliği açısından riskleri olan sağlık hizmetleri alanında faaliyet gösteren hastanelerde önem taşımaktadır. ILO sağlık çalışanlarını 5 farklı gruba ayırmakta olup, bu gruplardan birisini eğitim ve formasyon bakımından sağlık personeli olmayan, ancak sağlık kuruluşlarında sekreter, temizlik görevlileri gibi çalışanlar oluşturmaktadır. Sağlık hizmetleri; birçok bölümü içinde barındıran, bir ekip çalışması gerektiren ve farklı meslek gruplarıyla yürütülen hizmetlerdir. Bu ekip içerisinde "sahip olunan tüm kaynaklardan en üst düreyde yararlanarak, mevcut olanaklarla, temiæ, sağhkel, güvenli, düzenli, güzel bir çevre yaratma" amacını taşıyan ve bu amacinı hedeflenen standartlara ve ayrilan bütçeye bağlı kalarak, hastanelerin, temizlik, enfeksiyon kontrolü ve sanitasyon, fiziksel çevre düzenlemesi ve ev idaresi personelinin yönetimi gibi hizmet alanlarına ayırarak sağlayan (Şafak \& Erkal, 2011: 2) kurum ev idaresi hizmet alanı önemli bir yere sahiptir. Literatür incelendiğinde kurum ev idaresi personeliyle ilgili olarak yapılmış farklı çalışmalar bulunmakla birlikte (Kurt, vd., 2015; Yoldaş, Bulut, vd., 2014; Dikmen, vd., 2014; Sarı, vd., 2014; Bolubay ve Türkay, 2013; Çamözü \& Kitiş, 2011; Toraman, vd., 2011; Erkal \& Coşkuner, 2010; Terzi, vd., 2009; Erdem \& Talas, 2006) hastanelerde çalışan ve iş kazalarına sıkça uğrayan kurum ev idaresi personeli perspektifinden iş sağlığı ve güvenliği uygulamalarının ve güvenlik kültürüne ilişkin alg1 düzeylerinin belirlenmesi açısından bir çalışmaya rastlanmamış olması nedeniyle yapılan bu çalışma önem taşımaktadır.

\section{ARAŞTIRMANIN YÖNTEMİ}

Araştırmanın evreni; Ankara il sınırlanı içerisinde yer alan belirli alanlarda ihtisaslaşmış hastaneler, askeri hastaneler ile özel hastaneler dışında kalan ve Ankara il merkezindeki 50 yatak kapasitesinin üzerindeki T.C. Sağlık Bakanlığı’na ve üniversitelere bağlı çalışmayı kabul eden 14 hastanedeki toplam kurum ev idaresi personelidir $(\mathrm{N}=3510)$ Çalısmayı kabul eden her bir hastaneden çalışmaya katılacak personel sayısının belirlenmesinde ise orantılı örnekleme yöntemi kullanılmış olup, 400 kurum ev idaresi personeli ile çalışma yürütülmüştür.

Veri toplamak amacıyla anket formu hazırlanmıştır. Form hazırlanmadan önce araştırmada kullanılması planlanan ölçeklerin sahiplerinden gerekli izinler alınmıştır. Anket formu; katılımcılara ilişkin bireysel bilgilerin olduğu ilk bölüm, personelin iş sağllğı ve güvenliğine ilişkin bilgilerini ölçen ikinci bölüm, Demirbilek (2005) ve Demirbilek ile Çakır'ın (2008) çalısmalarından yararlanılarak oluşturulan "Güvenlik Kültürü Ölçeğinin" yer aldığ1 üçüncü bölüm ve Yorgun ve Atasoy (2013) tarafindan hazırlanan Çalışan Sağlığ1 ve Güvenliği Ölçeğinin olduğu dördüncü bölüm şeklinde oluşturulmuştur. 
Çiçek, B., \& Erkal, S. (2016). Hastanelerde kurum ev idaresi personeli perspektifinden iş sağllğ̆ ve güvenliği uygulamalarının ve güvenlik kültürüne ilişkin alg1 düzeylerinin belirlenmesi. Journal of Human Sciences, 13(3), 4416-4431. doi:10.14687/ihs.v13i3.3993

Araştırmada kullanılan "Güvenlik Kültürü Ölçeği” 4 alt boyuttan oluşmaktadır. Williamson (1997) tarafindan hazırlanıp, geçerlik güvenirlik çalışması Demirbilek ve Çakır (2008) tarafindan yapılan ve Türkçe'ye uyarlanan 'Güvenlik Uygulamaları' alt boyutu (Positive Safety Practice) 6 maddeden oluşmuştur. Cox ve Cheyne (2000) tarafindan hazırlanan, geçerlik güvenirlik çalısması Demirbilek (2005) tarafindan yapilan ve Türkçe'ye uyarlanan 'Yönetimin Bağllliğı' alt boyutu (Management Commitment) iş güvenliğine kurumun üst yönetiminin bağlllık düzeyini belirlemeyi amaçlayan 7 maddeden oluşmuştur ve ölçeğin bir sorusu olumsuz ifade olması nedeniyle ters kodlanmıştır. 'Güvenlik Önceliği' alt boyutu (Priority of Safety) kurum yönetimi açısından iş güvenliğinin taşıdığ1 önem düzeyini saptayan 4 maddeden oluşmuştur ve ölçeğin bir sorusu olumsuz ifade olması nedeniyle ters kodlanmıştır. 'Güvenlik İletişimi' alt boyutu (Communication) ise iş güvenliği alanındaki konu, bilgi ve haberlere ilişkin kurumdaki iletişim düzeyini belirlemek amacıyla 5 maddeden oluşmuştur ve ölçeğin iki sorusu olumsuz ifade olması nedeniyle ters kodlanmıştır. Ölçekte yer alan ifadelerin yanıt kategorileri 5' li derecelemeye göre hazırlanmış olup, "tamamen katıllyorum" (5 puan) ve "tamamen katılmıyorum" (1 puan) arasında değişmektedir.

Çalışmada kullanılan Yorgun ve Atasoy (2013) tarafindan hazırlanan "Çalışan Sağlığı ve Güvenliği Ölç̧eği” 8 alt boyuta ayrilmıştır. 'Enfeksiyonu Önleme' alt boyutu 6 maddeden, 'Yönetim Politikalarr' alt boyutu 7 maddeden, 'Sağlık Taramaları' alt boyutu 6 maddeden, 'Kimyasal Madde Güvenliği' alt boyutu 4 maddeden, 'Güvenlik Eğitimleri' alt boyutu 5 maddeden, 'Şiddeti Önleme' alt boyutu 3 maddeden, 'Gıda Güvenliği’ alt boyutu 2 maddeden, 'Düşmeyi Önleme' alt boyutu ise 2 maddeden oluşmakta ve toplam 35 madde yer almaktadır. Yorgun ve Atasoy' un (2013) çalışmasında geçerlik güvenirlik katsayısı $\alpha=0.938$ 'dir. Ölçekte yer alan ifadelerin yanıt kategorileri 5' li derecelemeye göre hazırlanmış olup, "tamamen katiliyorum" (5 puan) ve "kesinlikle katılmıorum" (1 puan) arasında değişmektedir.

Toplanan verilerin istatistiksel analizleri IBM SPSS istatistiksel paket programı kullanılarak yapılmıştır. Test sonuçlarında elde edilen $\mathrm{p}$ değerleri $\% 95$ güven düzeyinde ve $\alpha=0,05$ anlamlılık düzeyinde değerlendirilmiştir. Sürekli verilerin karşılaşturilmasında 2 grupta Bağımsız. Gruplar İ̧̧in $t$ Testi, 3 ve daha fazla grupta Varyans Analizi (ANOVA) Testi kullanılmıştur. ANOVA Testi sonucunda istatistiksel olarak anlamlı fark saptandığı durumlarda ikili karşılaştırmalar için Tukey Testi kullanılmıştır.

$\mathrm{Bu}$ çalışma, hastanelerde çalışan kurum ev idaresi personeline uygulanacağından dolayı “Çalışan Sağllğı ve Güvenliği Ölçeğì”nde ev idaresi personeli ile ilgisi olmayan 'Güvenlik Eğitimleri' alt boyutundan "Kurşun önlük kontrolleri yapıllır." Maddesi ölçek sahibinden alınan izin dâhilinde çıkarılmıştır. Bu nedenle doğrulayıcı faktör analizi yapılmıştır.

\section{Doğrulayıcı Faktör Analizi Sonuçları}

Çalışan Sağllğı ve Güvenliği Ölçeği hastanelerde çalışan kurum ev idaresi personeline uygulanacağından personelle ilgisi olmayan 'Güvenlik Eğitimleri' alt boyutundan 'Kurşun önlük kontrolleri yapılır." maddesi alınan izin dâhilinde çıkarılarak faktör yapısının uygunluğunu belirlemek amacıyla doğrulayıcı faktör analizi yapılmış ve Şekil 1'de görülen model oluşturulmuştur. 
Çiçek, B., \& Erkal, S. (2016). Hastanelerde kurum ev idaresi personeli perspektifinden iş sağllğı ve güvenliği uygulamalarının ve güvenlik kültürüne ilişkin alg1 düzeylerinin belirlenmesi. Journal of Human Sciences, 13(3), 4416-4431. doi:10.14687/jhs.v13i3.3993

\section{Şekil 1: Doğrulayıcı Faktör Analizi Diyagramı}

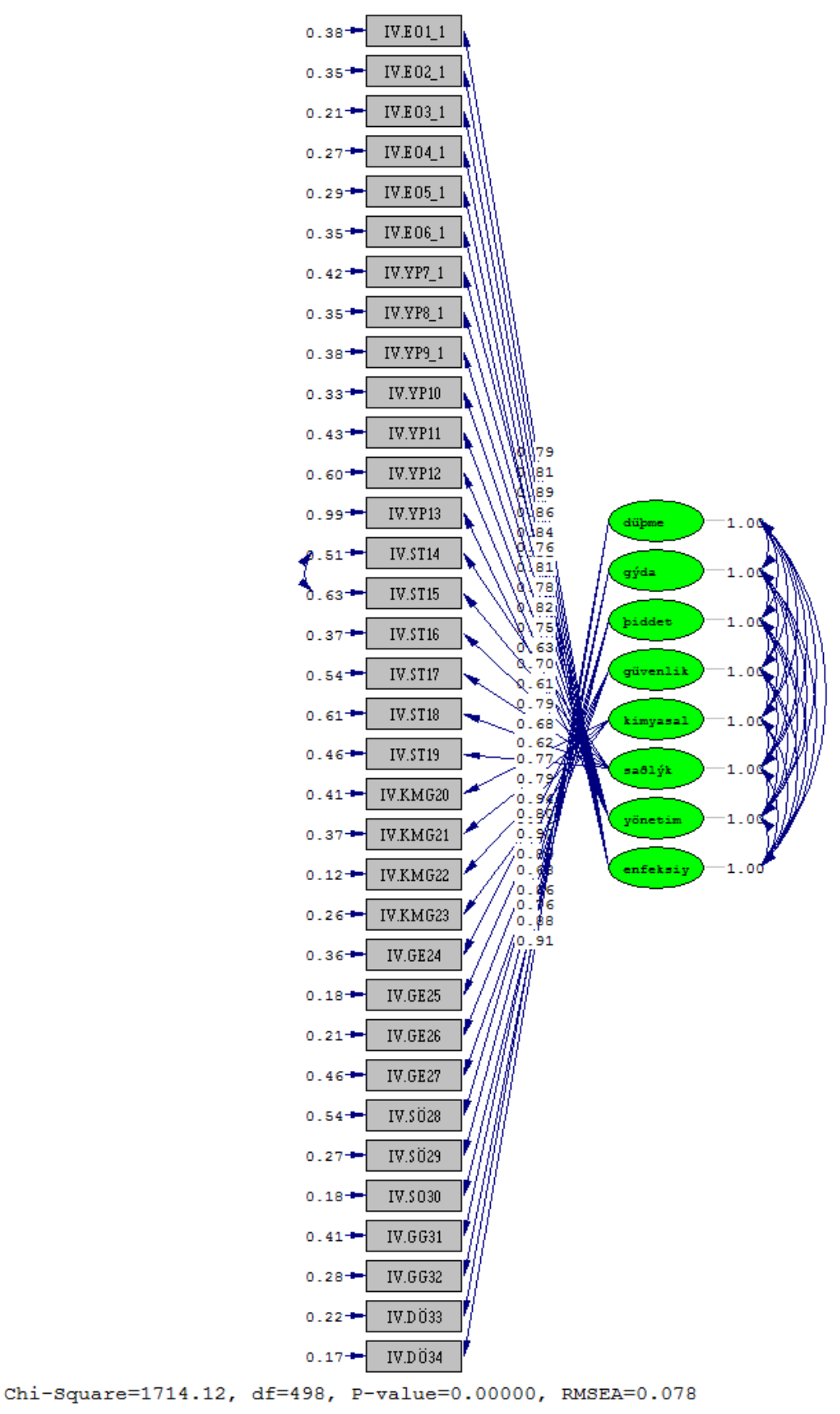

Şekil 1'de, DFA için faktör yük değerlerinin .61 ile .94 arasında, hata varyans değerlerinin .12 ile .99 arasında olduğu ve tamamının anlamlı bir düzeye ulaştığı görülmektedir. 
Çiçek, B., \& Erkal, S. (2016). Hastanelerde kurum ev idaresi personeli perspektifinden iş sağllğ̆ ve güvenliği uygulamalarının ve güvenlik kültürüne ilişkin alg1 düzeylerinin belirlenmesi. Journal of Human Sciences, 13(3), 4416-4431. doi:10.14687/ihs.v13i3.3993

Tablo. 1: Doğrulayıc1 Faktör Analizi Uyum İyiliği İndeksi Değerleri

\begin{tabular}{|c|c|c|c|c|c|c|c|c|c|c|}
\hline $\boldsymbol{X}^{2}$ & $\boldsymbol{s} \boldsymbol{d}$ & $\boldsymbol{x}^{2} / \boldsymbol{s} \boldsymbol{d}$ & $\boldsymbol{p}$ & $\mathbf{I F I}$ & $\mathbf{C F I}$ & $\mathbf{N F I}$ & $\mathbf{N N F I}$ & SRMR & RMSEA & $\begin{array}{c}\text { \% 90 C.J. } \\
\text { RMSEA }\end{array}$ \\
\hline 1714.12 & 498 & 3.44 & 0.0 & .97 & .97 & .96 & .96 & .058 & .078 & .074 .082 \\
\hline
\end{tabular}

DFA sonuçlarına göre elde edilen uyum indeksi değerleri Tablo 1'de görüldüğü gibi $X^{2}=1714.12, s d=498, \mathrm{IFI}=.97, \mathrm{CFI}=.97, \mathrm{NFI}=.96, \mathrm{NNFI}=.96, \mathrm{SRMR}=.058$ ve $\mathrm{RMSEA}=.074-$ .082 olarak hesaplanmıştır. Ki-kare değeri anlamlı çıkmışır, bu durum araştırmaya alınan kişi sayısının fazlalığından kaynaklanabilir. Çalışmaya alınan kişi sayısı arttıkça uyum arttı̆̆ bilinmektedir (Hu \& Bentler, 1999). Ki-kare değerinin serbestlik derecesine oranı $\left(c^{2}=x^{2} / s d\right) 3.44$ olarak hesaplanmıştır. Bu oranın 5'ten küçük olması ile RMSEA (.074-.082), SRMR (.058), IFI (.97), CFI (.97), NFI (.96) ve NNFI (.96) değerleri incelendiğinde kabul edilebilir düzeyde uyum gösterdikleri anlaşlmaktadır. Bu uyum indekslerinden RMSEA .06 veya daha az bir değere, SRMR .08 ya da daha az, CFI, IFI, NFI ve NNFI ise .90 ve üstü bir değer model için kabul edilebilir uyumun göstergesi, .95 ve üstü iyi bir uyum indeksi olarak kabul edilmektedir (Hu \& Bentler, 1999). Araştırma modeli için RMSEA ve SRMR değerlerinin .10'dan küçük olması modelin kabul edilebilir düzeyde olduğunu göstermektedir (Yılmaz \& Çelik, 2009; Cole, 1987; Anderson \& Gerbing, 1984). Sonuç olarak; doğrulayıcı faktör analizinden elde edilen bulgular, faktör yapısının toplanan verilerle kabul edilebilir uyum gösterdiğine işaret etmektedir.

\section{BULGULAR}

\section{Kurum Ev İdaresi Personelinin Bireysel Bilgilerine İlişkin Bulgular}

Çalışmada, araştırmaya katılan personelin bireysel bilgilerine yönelik frekans ve yüzde dağılımları Tablo 2' de verilmiştir.

Araştırma kapsamına alınan kurum ev idaresi personelinin \% 52,0' si erkektir ve \% 23,5 ile 36-40 yaş grubunda olanlar ilk sırada gelmektedir. Personelin, \% 34,4'ü ilkokul mezunu ve daha az öğrenim düzeyine sahiptir. Personelin \% 77,5' i evlidir.

Personelin toplam hizmet yılına $(\% 36,0)$ ve çalş̧ı̆ğ hastanedeki hizmet yılına (\% 37,8) bakıldı̆̆ında; 1-5 yıldır çalışanlar önde gelmektedir. Çalışmaya katılan personelin \% 98,8' i hizmet içi eğitim aldığını belirtmiştir. Çalıştığı hastanede hizmet içi eğitim aldığını belirten personelin tamamı $(\%$ 100,0) 'İş Sağlığ1 ve Güvenliği’ konusunda eğitim almıştır. Kurum ev idaresi personelinin \% 98,5' i de işini yaparken eldiven, maske gibi kişisel koruyucu donanım kullandığını belirtmiştir (Tablo 2). 
Çiçek, B., \& Erkal, S. (2016). Hastanelerde kurum ev idaresi personeli perspektifinden iş sağllğ̆ ve güvenliği uygulamalarının ve güvenlik kültürüne ilişkin alg1 düzeylerinin belirlenmesi. Journal of Human Sciences, 13(3), 4416-4431. doi:10.14687/jhs.v13i3.3993

Tablo 2 : Kurum Ev İdaresi Personelinin Bireysel Bilgilerine Göre Dağı1ımı

\begin{tabular}{|c|c|c|c|c|c|c|c|c|}
\hline DEĞİŞKENLER & GRUPLAR & $\mathrm{n}$ & $\%$ & DEĞİŞKENLER & \multicolumn{2}{|c|}{ GRUPLAR } & $\mathrm{n}$ & $\%$ \\
\hline \multirow{2}{*}{ Cinsiyet } & Kadın & 192 & 48,0 & \multirow{5}{*}{$\begin{array}{c}\text { Çaliştı̆ğ Hastanedeki } \\
\text { Hizmet Ylh } \\
\text { (n:399) }\end{array}$} & \multicolumn{2}{|c|}{1 ylldan az } & 37 & 9,3 \\
\hline & Erkek & 208 & 52,0 & & \multicolumn{2}{|l|}{$1-5 \mathrm{yll}$} & 151 & 37,8 \\
\hline \multirow{8}{*}{ Yaş } & $18-24$ & 30 & 7,5 & & \multicolumn{2}{|l|}{$6-10 \mathrm{yll}$} & 124 & 31,1 \\
\hline & $25-30$ & 51 & 12,8 & & \multicolumn{2}{|c|}{$11-15$ yll } & 65 & 16,3 \\
\hline & $31-35$ & 84 & 21,0 & & \multicolumn{2}{|c|}{16 yll ve üzeri } & 22 & 5,5 \\
\hline & $36-40$ & 94 & 23,5 & \multirow{2}{*}{$\begin{array}{l}\text { Kurumda Hizmet İçi } \\
\text { Eg̈itim Alma Durumu }\end{array}$} & \multicolumn{2}{|l|}{ Evet } & 395 & 98,8 \\
\hline & $41-45$ & 74 & 18,5 & & \multicolumn{2}{|l|}{ Hayir } & 5 & 1,2 \\
\hline & $46-50$ & 46 & 11,5 & \multirow{10}{*}{$\begin{array}{c}\text { Hizmet İ̧i Eğitim } \\
\text { Konular1* }^{*} \\
\text { (n:395) }\end{array}$} & \multicolumn{2}{|c|}{ İş Sağlığı ve Güvenliği } & 395 & 100,0 \\
\hline & \multirow{2}{*}{51 ve üzeri } & \multirow{2}{*}{21} & \multirow{2}{*}{5,2} & & \multicolumn{2}{|c|}{ Temizlik Yöntemleri } & 374 & 94,7 \\
\hline & & & & & \multicolumn{2}{|c|}{ Enfeksiyon Kontrolü ve Sanitasyon } & 351 & 88,9 \\
\hline \multirow{3}{*}{$\begin{array}{c}\text { Öğrenim Düzeyi } \\
(\text { (n:399) }\end{array}$} & İlkokul ve altı mezunu & 137 & 34,4 & & \multicolumn{2}{|c|}{$\begin{array}{lll}\text { Araç Gereçlerin Kullanımı ve } \\
\text { Bakımı }\end{array}$} & 330 & 83,5 \\
\hline & Ortaokul Mezunu & 130 & 32,6 & & \multicolumn{2}{|c|}{ Kişisel Hijyen } & 338 & 85,6 \\
\hline & Lise ve üzeri mezunu & 132 & 33,0 & & \multicolumn{2}{|c|}{ Kazalardan Korunma } & 331 & 83,8 \\
\hline \multirow{3}{*}{ Medeni Durum } & Bekâr & 69 & 17,3 & & \multicolumn{2}{|c|}{ Temizlik Maddelerinin Kullanımı } & 341 & 86,3 \\
\hline & Evli & 310 & 77,5 & & \multicolumn{2}{|c|}{ Haşere Kontrolü } & 155 & 39,3 \\
\hline & Diğer (boşanmış, eşi ölmüşs) & 21 & 5,2 & & \multirow[b]{2}{*}{ Diğer } & İletişim & 3 & 0,7 \\
\hline \multirow{5}{*}{$\begin{array}{c}\text { Toplam Hizmet } \\
\text { Yilt }\end{array}$} & 1 yildan az & 30 & 7,4 & & & $\begin{array}{l}\text { Yangin } \\
\text { Söndürme } \\
\text { Eğitimi } \\
\end{array}$ & 4 & 1,0 \\
\hline & $1-5 \mathrm{yll}$ & 144 & 36,0 & \multirow{2}{*}{$\begin{array}{c}\text { Kisisel Koruyucu } \\
\text { Donanım Kullanma }\end{array}$} & \multicolumn{2}{|l|}{ Evet } & 394 & 98,5 \\
\hline & $6-10 \mathrm{yll}$ & 105 & 26,3 & & \multicolumn{2}{|l|}{ Hayır } & 6 & 1,5 \\
\hline & $11-15$ yl & 77 & 19,3 & & & & & \\
\hline & 16 ve üzeri & 44 & 11,0 & & & & & \\
\hline
\end{tabular}

* Personel hizmet içi eğitim konularına birden çok cevap vermiştir.

\section{Kurum Ev İdaresi Personelinin İş Kazası Geçirme Durumuna İlişkin Bulgular}

Araşturmaya katılan personelin iş kazası geçirme durumuna ilişkin frekans ve yüzde dağılımları Tablo 3' te verilmiştir.

Çalışmaya katılan personelin \% 10,3'ü iş kazası geçirmiştir. İş kazası geçiren kurum ev idaresi personeline kazanın nedenleri sorulduğunda; \% 63,9'u kazanın nedenini 'personelin güvenli olmayan davranışı', \% 36,1'i ise 'iş güvenliği olmayan çalışma ortamı' olarak belirtmiştir.

İş kazası geçiren personelin kaza tiplerine bakıldığında; \% 63,4 ile 'kesici delici alet yaralanması'na maruz kalanlar ilk sırada yer alırken, bunu, \% 34,1 ile 'düşme' sonucu kaza geçirenler izlemektedir. İş kazası geçirdiği sırada personele hangi işi yaptığ sorulduğunda ise \% 53,8 ile 'atıkları toplarken' kaza geçirdiğini belirtenler önde gelmektedir.

Personele genel olarak iş kazalarının nedenine ilişkin görüşleri sorulduğunda; \% 72,9’u 'personelin güvenli olmayan davranışının', \% 27,1'i ise 'iş güvenliğine uygun olmayan çalışma ortamının' neden olduğunu belirtmiştir.

Kurum ev idaresi personelinin çalıştı̆̆ hastane yönetiminin iş sağlı̆̆1 ve güvenliği ile ilgili uygulamalarına verdikleri önem sorulduğunda; personelin, $\%$ 40,3'ü 'önem verdiğini' düşünmektedir. 
Çiçek, B., \& Erkal, S. (2016). Hastanelerde kurum ev idaresi personeli perspektifinden iş sağllğı ve güvenliği uygulamalarının ve güvenlik kültürüne ilişkin alg1 düzeylerinin belirlenmesi. Journal of Human Sciences, 13(3), 4416-4431. doi:10.14687/ihs.v13i3.3993

Tablo. 3: Kurum Ev İdaresi Personelinin İş Kazası Geçirme Durumuna Göre Dağılımları

\begin{tabular}{|c|c|c|c|c|}
\hline DEĞİŞKENLER & & GRUPLAR & $\mathbf{n}$ & $\%$ \\
\hline \multirow{2}{*}{ İş Kazası Geçirme Durumu } & \multicolumn{2}{|c|}{ İș Kazası Geçirenler } & 41 & 10,3 \\
\hline & \multicolumn{2}{|c|}{ İş Kazası Geçirmeyenler } & 359 & 89,7 \\
\hline \multirow{2}{*}{ Geçirilen İş Kazasının Nedeni } & \multicolumn{2}{|c|}{ Personelin Güvenli Olmayan Davranışı } & 25 & 63,9 \\
\hline & \multicolumn{2}{|c|}{ İş Güvenliği Olmayan Çalışma Ortamı } & 16 & 36,1 \\
\hline \multirow{4}{*}{$\begin{array}{l}\text { Geçirilen İş Kazasının Tipi* } \\
\text { (n:41) }\end{array}$} & \multicolumn{2}{|c|}{ Düşme } & 14 & 34,1 \\
\hline & \multicolumn{2}{|c|}{ Kesici Delici Alet Yaralanmas1 } & 26 & 63,4 \\
\hline & \multicolumn{2}{|c|}{ Yanma ve Haşlanma } & 3 & 7,3 \\
\hline & \multicolumn{2}{|c|}{ Elektrik Carpmas1 } & 2 & 4,9 \\
\hline \multirow{10}{*}{$\begin{array}{l}\text { İş Kazası Geçirdiği Sırada Yapılan } \\
\text { İş* } \\
(\mathrm{n}: 41)\end{array}$} & \multicolumn{2}{|c|}{ Paspaslama İşlemi Yaparken } & 7 & 17,9 \\
\hline & \multicolumn{2}{|c|}{ Atıkları Toplarken } & 21 & 53,8 \\
\hline & \multicolumn{2}{|c|}{ Temizlik Araç Gereçlerini Kullanırken } & 5 & 12,8 \\
\hline & \multicolumn{2}{|c|}{ Tuvaletleri Temizlerken } & 2 & 5,1 \\
\hline & \multicolumn{2}{|c|}{ Essya Tașırken } & 6 & 15,4 \\
\hline & \multicolumn{2}{|c|}{ Cam Silerken } & 2 & 5,1 \\
\hline & \multirow{4}{*}{ Diğer } & Tavan takarken & 1 & 2,5 \\
\hline & & Hastaya refakat ederken & 1 & 2,5 \\
\hline & & Hafriyat atarken & 1 & 2,5 \\
\hline & & Otoklav cihazından kaynaklı & 1 & 2,5 \\
\hline \multirow{2}{*}{$\begin{array}{l}\text { Genel Olarak İş } \underset{\text { Kazasının }}{\text { Nedenine İlişkin Görüş (n:343) }} \\
\text { Nedin }\end{array}$} & \multicolumn{2}{|c|}{ Personelin Güvenli Olmayan Davranışı } & 250 & 72,9 \\
\hline & \multicolumn{2}{|c|}{$\begin{array}{l}\text { İs Güvenliğine Uygun Olmayan Çalışma } \\
\text { Ortamı }\end{array}$} & 93 & 27,1 \\
\hline \multirow{4}{*}{$\begin{array}{l}\text { Hastane Yönetiminin "İ̧̇ Sağlığı ve } \\
\text { Güvenliği İle İlgili Uygulamalarına" } \\
\text { Önem Verme Durumuna İlişkin } \\
\text { Görüş (n:397) }\end{array}$} & \multicolumn{2}{|c|}{ Hiç Önem Vermiyor } & 39 & 9,8 \\
\hline & \multicolumn{2}{|c|}{ Biraz Önem Veriyor } & 111 & 28,0 \\
\hline & \multicolumn{2}{|c|}{ Önem Veriyor } & 160 & 40,3 \\
\hline & \multicolumn{2}{|c|}{ Çok Önem Veriyor } & 87 & 21,9 \\
\hline
\end{tabular}

*Personel sorulara birden çok cevap vermiştir.

Kurum Ev İdaresi Personelinin Güvenlik Kültürü ve Çalışan Sağlı̆̆1 Güvenliği Kültürüne İlişkin Alg1 Düzeylerinin Bireysel Özelliklerine Göre Dağılımına Yönelik Bulgular

Tablo 4'e göre; kurum ev idaresi personelinin 'Güvenlik Kültürü'ne ilisskin alg1 düzeyleri ile personelin hastane yönetiminin iş sağllğı ve güvenliği ile ilgili uygulamalanına önem verme durumuna ilişkin görüşleri, araç gereçlerin kullanımı ve bakımı, kazalardan korunma ve temizlik maddelerinin kullanımı konularına ilişkin eğitim alma durumu arasında istatistiksel olarak anlamlı farkll11k $(\mathrm{p}<0,05)$ bulunurken; cinsiyet, yaş, toplam hizmet y1l, öğrenim düzeyi, medeni durum, çalıştığı hastanedeki hizmet yılı, çalıştığı hastanede iş kazası geçirme durumu, geçirilen iş kazasının nedeni, genel olarak iş kazalarının nedenine ilişkin görüşleri, temizlik yöntemleri, enfeksiyon kontrolü ve sanitasyon ile kişisel hijyenle ilgili eğitim alma durumlan arasında istatistiksel olarak anlamlı farklilik $(\mathrm{p}>0,05)$ bulunmamıştır.

Kurum ev idaresi personelinin 'Çalışan Sağllğı ve Güvenliği Kültürü’ne ilişkin alg1 düzeyleri ile yalnızca personelin hastane yönetiminin iş sağlı̆̆1 ve güvenliği ile ilgili uygulamalarına önem verme durumuna ilişkin görüşleri arasında istatistiksel olarak anlamlı farklılık $(p<0,05)$ bulunurken; cinsiyet, yaş, öğrenim düzeyi, medeni durum, toplam hizmet yıll, çalıştı̆̆ hastanedeki hizmet yıll, çalıştığı hastanede iş kazası geçirme durumu, geçirilen iş kazasının nedeni, genel olarak iş kazalarının nedenine ilişkin görüşler, temizlik yöntemleri, enfeksiyon kontrolü ve sanitasyon, araç gereçlerin kullanımı ve bakımı, kişisel hijyen, kazalardan korunma ve temizlik maddelerinin kullanımı konularına ilişkin eğitim alma durumu arasında istatistiksel olarak anlamlı farklılık $(\mathrm{p}>0,05)$ bulunmamıştır. 
Çiçek, B., \& Erkal, S. (2016). Hastanelerde kurum ev idaresi personeli perspektifinden iş sağllğ̆ ve güvenliği uygulamalarının ve güvenlik kültürüne ilişkin alg1 düzeylerinin belirlenmesi. Journal of Human Sciences, 13(3), 4416-4431. doi:10.14687/jhs.v13i3.3993

Tablo. 4: Kurum Ev İdaresi Personelinin Güvenlik Kültürü ve Çalışan Sağlığı Güvenliği Kültürüne İlişkin Algı Düzeylerinin Bireysel Özelliklerine Göre Dağılımı

\begin{tabular}{|c|c|c|c|c|}
\hline \multirow{2}{*}{ Bireysel Değişkenler } & \multicolumn{2}{|c|}{ Güvenlik Kültürü Ölçeği } & \multicolumn{2}{|c|}{$\begin{array}{l}\text { Çalışan Sağlığı ve Güvenliği } \\
\text { Kültürü Ölçeği }\end{array}$} \\
\hline & t/F değeri & p değeri & t/F değeri & p değeri \\
\hline Cinsiyet &,- 152 & 0,734 & 1,407 & 0,158 \\
\hline Yaş Grupları & 2,086 & 0,044 & 1,437 & 0,263 \\
\hline Öğrenim Düzeyi & 2,433 & 0,815 & 1,277 & 0,267 \\
\hline Medeni Durum & 056 & 0,754 & 600 & 0,539 \\
\hline Toplam Hizmet Y1lı & 911 & 0,785 & 2,230 & 0,062 \\
\hline Çalıştı̆̆1 Hastanedeki Hizmet Yılı &, 571 & 0,583 & 1,171 & 0,338 \\
\hline Çalışılan Hastanede İş Kazası Geçirme Durumu & $-1,110$ & 0,326 & ,399 & 0,759 \\
\hline Geçirilen İş Kazasının Nedeni & 171 & 0,473 & ,346 & 0,797 \\
\hline $\begin{array}{l}\text { Genel Olarak İş Kazalarının Nedenlerine Yönelik } \\
\text { Görüşler }\end{array}$ & 2,624 & 0,371 &,- 866 & 0,417 \\
\hline $\begin{array}{l}\text { Hastane Yönetiminin İş Sağlığı ve Güvenliği İle } \\
\text { İlgili Uygulamalara Önem Verme Durumuna } \\
\text { İlişkin Görüşler }\end{array}$ & 17,152 & $0,000 *$ & 10,775 & $0,000 *$ \\
\hline Temizlik Yöntemleri Eğitimi &,- 512 & 0,327 & $-1,589$ & 0,100 \\
\hline Enfeksiyon Kontrolü ve Sanitasyon Eğitimi & $-1,213$ & 0,937 & 1,156 & 0,250 \\
\hline Araç Gereçlerin Kullanımı ve Bakımı Eğitimi & $-2,167$ & $0,029 *$ &,- 777 & 0,404 \\
\hline Kişisel Hijyen Eğitimi & $-1,810$ & 0,142 &,- 273 & 0,738 \\
\hline Kazalardan Korunma Eğitimi & $-3,396$ & $0,007 *$ &,- 396 & 0,599 \\
\hline Temizlik Maddelerinin Kullanımı Eğitimi & $-2,271$ & $0,020 *$ &,- 100 & 0,845 \\
\hline
\end{tabular}

\section{TARTIŞMA}

Araştırma kapsamına alınan kurum ev idaresi personeli arasında erkekler (\% 52,0), 36-40 yaş grubundakiler (\% 23,5), ilkokul ve daha az öğrenim düzeyinde olanlar (\% 34,4) ve evliler $(\%$ 77,5) önde gelmektedir. Personelin toplam hizmet yilı $(\% 36,0)$ ve bulunduğu hastanedeki hizmet yılı (\% 37,8) 1-5 yıl arasında olanlar ilk sırada yer almaktadır. Gürsoy’un (2013) çalışmasında ise kurum ev idaresi personelinin \% 34,4'ünün lise, \% 25,0'inin ortaokul, \% 24,1'inin ise ilkokul mezunu olduğu belirlenmiştir. Köse, vd.'nin (2011) çalışmasında, personelin \%25.2'sinin 1-5 yıldır bulunduğu hastanede çalıştığı belirlenmiştir.

Ev idaresi personelinin \% 98,8’i hizmet içi eğitim aldığını belirtmiştir. Çalışı̆̆̆ hastanede hizmet içi eğitim aldığını belirten personelin (\% 100,0) tamamı 'İş Sağlığ1 ve Güvenliği' konusunda eğitim almıştır. Ev idaresi personelinin \% 98,5’i işini yaparken eldiven, maske gibi kişisel koruyucu donanım kullandığını belirtmiştir.

Hastanelerde çalışan ev idaresi personeli yaptı̆̆ iş gereği her an risk ve tehlikelerle karşı karşıya kalmakta, bu durum da personelin iş kazası geçirme olasılığını artırmaktadır (Şafak \& Erkal, 
Çiçek, B., \& Erkal, S. (2016). Hastanelerde kurum ev idaresi personeli perspektifinden iş sağllğ̆ ve güvenliği uygulamalarının ve güvenlik kültürüne ilişkin alg1 düzeylerinin belirlenmesi. Journal of Human Sciences, 13(3), 4416-4431. doi:10.14687/ihs.v13i3.3993

2011; Yertutan, 2000). Çalışmamızda araşturmaya katılan ev idaresi personelinin \% 10,3’ü iş kazası geçirmiştir. Çamözü ve Kitiş’in (2011) çalışmasında araştırmaya katılan 99 personelden 36'sının; Toraman, vd.'nin (2011) çalışmasında meydana gelen 14 iş kazasının 9'unun; Erkal ve Coşkuner'in (2010) çalışmasinda araştırmaya katılan 184 personelin \% 19,0’unun; Gemalmaz'ın (2009) çalışmasında personelin yarıya yakınının (\% 41,0); Kuruüzüm, vd.'nin (2008) 42 personelle yürüttükleri çalısmada personelin yarıdan fazlasının (\% 57,8) kurum ev idaresi personelinin yaşadığı belirtilmiştir.

İş kazası geçiren kurum ev idaresi personelinin \% 53,8'i 'atıklar1 toplarken', \% 17,9’u 'paspaslama işlemi yaparken', \% 15,4'ü 'eşya taşırken', \% 12,8’i ‘temizlik araç gereçlerini kullanırken', \% 5,1'i eşit oranlarla 'tuvaletleri temizlerken' ve 'cam silerken' kaza geçirmiştir. İş kazası geçirenlerin yaşadıklanı kaza tiplerine bakıldığında; \% 63,4 ile 'kesici delici alet yaralanmasına maruz kalanlar' ilk sırada yer alırken, bunu \% 34,1 ile 'düşme', \% 7,3 ile 'yanma ve haşlanma', \% 4,9 ile de 'elektrik çarpması' sonucu kaza geçirenler izlemektedir. Kurt, vd.'nin (2015) araştırmasında; geçirilen iş kazaları arasında 'kesici delici alet' yaralanmalarının yer aldığı; Yoldaş, Bulut, vd.'nin (2014) çalışmasında; araştırmaya katılan temizlik personelinin (36 personel) \% 41,6'sının (15 personel) son bir yılda en az bir defa ele 'iğne batması' sonucu kaza geçirdiği sonucuna varılmıştır. Aynı şekilde Dikmen vd.'nin (2014) çalışmasında araştırmaya katılan sağlık çalışanlarının \% 63,4 ü meslek hayatı boyunca en az bir kere kesici-delici-batıcı cisimlerle yaralandığı; Sarı, vd.'nin (2014) çalışmasında, meydana gelen 229 delici kesici alet yaralanmasina \% 34,0 ile (78 personel) temizlik personelinin maruz kaldığı belirtilmiştir. Bolubay ve Türkay (2013) tarafından yürütülen çalışmada; ev idaresi personelinin en fazla 'iğne batması'na maruz kalındığı belirlenmiştir. Toraman, vd.'nin (2011) çalışmasında kurum ev idaresi personelinin karşılaştığı kazaların 'tıbbı atıkların taşınması', 'kesici delici alet kutularının boşaltılması', 'banyo temizliği yapılması' sırasında yaşandığı belirlenmiştir. Bu durum, sağlık çalışanları tarafindan kesici delici aletlerin bu aletlerin atılması için yapılmış delinmeye dayanıklı atık kutularının yerine, evsel atık torbalarına veya çöp kovalarına atılmasından ya da ev idaresi personelinin attkları toplarken koruyucu giysi kullanmamalarından kaynaklanıyor olabilir. Personelin en fazla atık toplarken kaza geçirmesi, atıkların toplanması, taşınması bu konuya ilişkin olası risklerle ilgili bilinçlendirilmeleri gerektiğini düşündürmektedir.

İş kazası geçiren ev idaresi personeline geçirdikleri iş kazasının nedeni sorulduğunda bireylerin \% 63,9'u iş kazasının 'personelin güvenli olmayan davranış1', \% 36,1'i ise 'iş güvenliği olmayan çalışma ortamından' kaynaklandığını belirtmiştir. Bu sonucun aksine Demirbilek ve Çakır'ın (2008) tekstil sektöründe çalışanlarla yürüttükleri çalısmasında iş kazalarının; personelin \% $53,5 ’ i$ 'iş güvenliği olmayan çalışma ortamından', \% 45,3’ü 'personelin güvenli olmayan davranışından’ kaynaklandığını belirtmişlerdir. Bu farklılık iki çalışmanın örneklemini oluşturan personelin farklı meslek gruplarına mensup olmasından, dolayısıyla da çalışma ortamındaki risk ve tehlikeler ile personelin sergilediği 'güvenli ya da güvenli olmayan davranışların' yapılan işe göre farklılaşmasından kaynaklanıyor olabilir.

Çalıştığı hastane yönetiminin iş sağllğı ve güvenliği ile ilgili uygulamalara verdikleri önemi belirten 397 kurum ev idaresi personelinin \% 40,3’ü mevcut uygulamalara 'önem verdiğini’, \% 28,0’i 'biraz önem verdiğini', \% 21,9'u 'çok önem verdiğini' düşünmektedir.

Çalışmada Kurum ev idaresi personelinin Çalışan Sağlığı ve Güvenliği Kültürü alg1 düzeyleri ve Güvenlik Kültürüne ilişkin alg1 düzeyleri ile hastane yönetiminin "iş sağllğ1 ve güvenliği ile ilgili uygulamalarına" önem verme durumuna ilişkin görüşleri arasında istatistiksel olarak anlamlı farklılık $(p<0,05)$ bulunmuştur. Personelin 'Güvenlik Kültürü’ne ilişkin alg1 düzeyi, hastane yönetiminin ilgili uygulamalara verdiği önem derecesi arttıkça artmaktadır. Kurum ev idaresi personeli arasında hastane yönetiminin ilgili uygulamalarına 'Çok önem veriyor' görüşüne sahip olanların 'Çalışan Sağlığ1 ve Güvenliği Kültürü’ne ilişkin alg1 düzeyi ortalaması diğerlerine oranla yüksek olarak bulunmuştur. Bu sonuçlara göre personel, genel olarak hastane yönetiminin iş sağllğ̆ ve güvenliği uygulamalarına çok önem verdiğini, konuyla ilgili çalışmalar yaptığını, eğitimler verdiğini, personelin iş sağlığını ve güvenliğini önemsediğini düşünmektedir. 
Çiçek, B., \& Erkal, S. (2016). Hastanelerde kurum ev idaresi personeli perspektifinden iş sağllğı ve güvenliği uygulamalarının ve güvenlik kültürüne ilişkin alg1 düzeylerinin belirlenmesi. Journal of Human Sciences, 13(3), 4416-4431. doi:10.14687/jhs.v13i3.3993

Kurum ev idaresi personelinin 'Güvenlik Kültürü'ne ilişkin alg1 düzeyleri ile 'Araç Gereçlerin Kullanımı ve Bakımı', 'Kazalardan Korunma' ve 'Temizlik Maddelerinin Kullanımı' ilgili eğitim alma durumları arasında istatistiksel olarak anlamlı farkllık $(\mathrm{p}<0,05)$ bulunmuştur. Konularla ilgili eğitim alanların 'Güvenlik Kültürü’ne ilişkin alg1 düzeyleri, eğitim almayanlara oranla daha yüksektir. Bu sonuçlar; verilen eğitimin yararlı ve etkili olduğunu göstermektedir.

\section{SONUÇ VE ÖNERİLER}

Araşturma sonucunda elde edilen verilere göre; kurum ev idaresi personelinin tamamına yakınının hizmet içi eğitim aldığı, hizmet içi eğitim alan personel arasında 'Işs Sağlı̆̆1 ve Güvenliği 'konusunda eğitim alanlar ilk sırada yer almaktadır. Aynı zamanda personelin \% 10,3'ünün iş kazası geçirdiği belirlenmiştir. İş kazası geçiren personelin yarıdan biraz fazlası 'atıkları toplarken' kaza geçirmiş olup, geçirilen kaza tipleri arasında; 'kesici delici alet yaralanmalarını' belirtenler ilk sırada yer almaktadır. Kurum ev idaresi personelinin 'Güvenlik Kültürü' ile 'Çalışan Sağlığ1 ve Güvenliği Kültürü'ne ilişkin alg1 düzeyleri ile personelin hastane yönetiminin iş sağlığ1 ve güvenliği ile ilgili uygulamalarına önem verme durumuna ilişkin görüşleri, araç gereçlerin kullanımı ve bakımı, kazalardan korunma ve temizlik maddelerinin kullanımı konularına ilişkin eğitim alma durumu arasında istatistiksel olarak anlamlı farklılık $(p<0,05)$ bulunurken; cinsiyet, yaş, toplam hizmet yıll, öğrenim düzeyi, medeni durum, çalıştı̆̆ı hastanedeki hizmet yılı, çalıştı̆̆ hastanede iş kazası geçirme durumu, geçirilen iş kazasının nedeni, genel olarak iş kazalarının nedenine ilişkin görüşleri, temizlik yöntemleri, enfeksiyon kontrolü ve sanitasyon ile kişisel hijyenle ilgili eğitim alma durumları arasında istatistiksel olarak anlamlı farklılık $(p>0,05)$ bulunmamıştır.

Kurum ev idaresi personelinin yaşadıkları kazaların 'önlenebilir kazalar' olduğu ve personelin güvenli olmayan davranışları sonucu meydana geldiği görülmektedir. Personelin bireysel bilgileri ile 'Güvenlik Kültürü’ ile 'Çalışan Sağllğı ve Güvenliği Kültürü’ne ilisskin alg1 düzeyleri arasında anlamlı bir ilişki bulunamadığından dolayı her çalışanın kaza riskinin olduğu söylenebilir. $\mathrm{Bu}$ nedenle iş kazalarını önlemek, güvenli davranışlanı benimsetmek, hastanelerde iş sağlığı ve güvenliğini, güvenlik kültürünü daha etkili şekilde oluşturmak ve sürekliliğini sağlayabilmek için ilgili kurum ve kuruluşlara, hastane yönetimlerine, işveren şirketlere, tüm hastane çalışanlarına ve kurum ev idaresi personeline şu önerilerde bulunulabilir:

- İsse yeni personel alımlarında verilen oryantasyon eğitimine iş sağllğı ve güvenliği konularının da dahil edilerek, personelin iş yaparken karşılaşacağı risk ve tehlikeler hakkında bilgilendirilmesi, personelin yeteneğine uygun işlerde çalıştırılması ve iş tanımı dışında başka işlerin yaptırılmaması sağlanarak risk ve tehlikelere karşı korunması,

- Kurum ev idaresi personelinin yaşadığ iş kazaları içerisinde en fazla kesici delici alet yaralanmalarının yer aldığı hem bu çalışmada hem de konuyla ilgili olarak yapılan diğer çalışmalarda görülmektedir. Genellikle atıkların toplanması esnasında yaşanılan kesici delici alet yaralanmalarına neden olan durumların (personelin koruyucu donanım kullanmaması, sağlık çalışanlarının tıbbı atıkları evsel çöp kutularına atması vb.) önlenmesi için gerekli çalışmaların yapılması, gerekli yerlere uyarıcı yazı ve levhaların asılması,

- Meydana gelebilecek iş kazaları ve meslek hastalıklarıyla ilgili olarak önlem alınması açısından iş kazası geçiren personelin tanımlayıcı bilgileri ile yaşanmış tüm iş kazalarının ve meslek hastalıklarının oluş biçimi, büyüklüğü, şiddeti ve sonuçları ne olursa olsun kayıt altına alınması, böylece kaza nedenlerinin belirlenmesi ve yüksek risk grubunda olanlara yönelik önlemlerin alınması,

- $\mathrm{Bu}$ çalışmada iş kazalarının genellikle güvenli olmayan davranışlardan kaynaklandığı sonucuna varılmıştır. Kurum ev idaresi personelinin hizmet içi eğitim almasına rağmen bunu uygulamaya yansıtamadıkları görülmektedir. $\mathrm{Bu}$ nedenle; personelin "güvenli 
Çiçek, B., \& Erkal, S. (2016). Hastanelerde kurum ev idaresi personeli perspektifinden iş sağllğ̆ ve güvenliği uygulamalarının ve güvenlik kültürüne ilişkin alg1 düzeylerinin belirlenmesi. Journal of Human Sciences, 13(3), 4416-4431. doi:10.14687/jhs.v13i3.3993

davranış" sergilemelerini sağlayacak şekilde üst yönetim tarafından etkili eğitim programlarının hazırlanması, güvenli davranışın yerleşmesi için düzenli ve sürekli olarak iş sağllğı ve güvenliği konularını da içeren eğitimlerin gerek iş başında gerekse iş dışında verilerek güvenlik kültürü bilincinin oluşturulması ve verilen eğitimin niteliğine yönelik ölçme çalışmalarının yapılması,

- Güvenlik kültürünün kurumda oluşturulabilmesi ve etkili bir şekilde sürdürülebilmesi için tüm personelin 'Güvenlik Uygulamaları', 'Yönetimin Bağlllı̆̆1', 'Güvenlik Önceliği' ve 'Güvenlik İletişimi' konularında bilinçlendirilmesi ve bu bilinci çalışma yaşamına aktarmasının sağlanması,

- Yöneticilerin iş güvenliği konusundaki kararlılı̆̆1 çalışanların üzerinde etkili olduğundan, güvenlik kültürü oluşturmada yönetimin kararlı bir şekilde davranması,

- Güvenlik kültürünün belirlenmesinde, anket yöntemiyle birlikte gözlem yönteminin kullanılması ile daha etkili sonuçlar alınabileceğinden bu çalışmadan hareketle Türkiye genelinde daha kapsamlı çalışmaların yapılması önerilebilir.

\section{KAYNAKÇA}

Akalp, G. \& Yamankaradeniz, N. (2013). İşletmelerde Güvenlik Kültürünün Oluşumunda Yönetimin Rolü ve Önemi. Sosyal Güvenlik Dergisi, 3(2), 96-109.

Aktay, N. (2011). İş Sağlığ1 ve Güvenliği Eğitimi ile İş Güvenliği Kültürü Arasındaki İlişki. T.C. Çalışma ve Sosyal Güvenlik Bakanlı̆̆ İş Teftiş Kurulu Başkanlığı, İstanbul.

Anderson, C. J. \& Gerbing, W. D. (1984). The Effect of Sampling Error on Convergence, Improper Solutions and Goodness-of-fit Indices for Maximum Likelihood Confirmatory Factor Analysis. Psychometrika, 49, 155-173.

Aytaç, S. (2011). İş Kazalarını Önlemede Güvenlik Kültürünün Önemi. Türk Metal Dergisi, 147, 1-8. Balkır, Z. G. (2012). İş Sağlığ1 ve Güvenliği Hakkının Korunması: İşverenin İş Sağlığ1 ve Güvenliği Organizasyonu. Sosyal Güvenlik Dergisi, 2(1), 56-91.

Bilir, N. \& Yıldız, A. N. (2014). İş Sağlı̆̆ı ve Güvenliği. Ankara: Hacettepe Üniversitesi Yayınları.

Bolubay, Ö. \& Türkay, M. (2013). Akdeniz Üniversitesi Hastanesi’nde Çalışan Hemşire ve Ev İdaresi Personelinin İş Kazası Geçirme Durumlarının İncelenmesi. VII. İşçi Sağlığı ve İş Güvenliği Kongresi, 18-20 Nisan 2013, Adana.

Bostanc1, Y. (2011). İşverenin İş Sağllğ1 ve Güvenliğine İlişkin Yükümlülüklerini Yerine Getirmemesi ve Yaptrmmları. Selguk Üniversitesi Hukuk Fakültesi Dergisi, 12(1-2), 67-86.

Camkurt, M. Z. (2013). Çalışanların Kişisel Özelliklerinin İş Kazalarının Meydana Gelmesi Üzerindeki Etkisi. TÜHİS Iss Hukuku ve İktisat Dergisi, 24(6)/ 25(1-2), 70-101.

Cole, A. D. (1987). Utility of Confirmatory Factor Analysis in Test Validation Research. Journal of Consulting and Clinical Psychology, 55, 1019-1031.

Cox, J. S. \& Cheyne, J. T. A. (2000). Assessing Safety Culture in Offshore Environments. Safety Science, 34, 111-129.

Çamözü, E. \& Kitiş, Y. (2011). Hastane Temizlik Hizmetleri Personelinin Tibbi Attkların Toplanması, Taşınması ve Depolanması İle İlgili Bilgi ve Uygulamalarının Belirlenmesi. TAF Preventive Medicine Bulletin,10(6), 631-640.

Demirbilek, T. (2005). İş Güvenliği Kültürü. İzmir: Legal Yayıncılık.

Demirbilek, T. \& Çakır,Ö. (2008). Kişisel Koruyucu Donanım Kullanımını Etkileyen Bireysel ve Örgütsel Değişkenler. Dokuz. Eylül Üniversitesi İktisadi ve İdari Bilimler Fakültesi Dergisi, 23(2), 173-191.

Dikmen Uğraş, A., Medeni, V., Uslu, İ., Aycan, S. (2014). Ankara’da Bir Üniversite Hastanesinde Çalışan Sağlık Personelinin Geçirdiğini İfade Ettiği İş Kazalarının Değerlendirilmesi. Türk Tabipleri Birlï̆i Mesleki Sağhk ve Güvenlik Dergisi, 22-29. 
Çiçek, B., \& Erkal, S. (2016). Hastanelerde kurum ev idaresi personeli perspektifinden iş sağllğ̆ ve güvenliği uygulamalarının ve güvenlik kültürüne ilişkin alg1 düzeylerinin belirlenmesi. Journal of Human Sciences, 13(3), 4416-4431. doi:10.14687/jhs.v13i3.3993

Erdem, Y. \& Talas, M.S. (2006). Blunt and Penetrating Object Injuries in Housekeepers Working in a Turkish University Hospital. American Journal of Infection Control, 34(4), 208-214.

Erkal, S. \& Coşkuner, S. (2010). Bir Hastanede Çalışan Ev İdaresi Personelinin İş Kazası Geçirme Durumunun ve Kazalardan Korunmak İçin Aldıkları Önlemlerin İncelenmesi. Hacettepe Sağhlk İdaresi Dergisi, 13(1), 46-61.

Gemalmaz, A. (2009). Bir Eğitim ve Araştırma Hastanesinde Görev Yapan Temizlik Personelinin Kurumda Çalıştıkları Süre Boyunca İş Kazası Geçirme Durumları ve Son KazaYaralanmaya Ait Özelliklerin Belirlenmesi. Yüksek Lisans Tezi, Sağllk Bilimleri Enstitüsü, Gazi Üniversitesi, Ankara.

Gürsoy, N. (2013). Hastane Çalışanlanının İş doyumu ve Tükenmişlik Durumlarının Aile Yaşamına Etkisi: Kurum Ev İdaresi Personeli Üzerine Bir Uygulama. Yüksek Lisans Tezi, Sosyal Bilimler Enstitüsü, Hacettepe Üniversitesi, Ankara.

Güven, R. (2006). Güvenlik Kültürü Oluşumunda Eğitimin Önemi. Iss Sağhlğ ve Güvenliği Dergisi, 30, $5-12$.

Hu, Li-tze. \& Bentler, M. P. (1999). Cutoff Criteria for Fit Indexes in Covariance Structure Analysis: Conventional Criteria Versus New Alternatives. Structural Equation Modeling, 6(1), $1-55$.

ILO (1998) http://laborsta.ilo.org/applv8/data/c8e.html Erişim Tarihi: 03.01.2016.

International Labour Conference [ILO]. (2009). ILO Standards On Occupational Safety And Health: Promoting A Safe And Healthy Working Environment, Report III, Geneva.

Keleş, R. (2004). İş Sağllğı ve İş Güvenliği Kavramı ve Kavramla İlgili Yeni Perspektifler. İs Sağhlğg ve Güvenliği Dergisi, 22.

Kılkış, İ. \& Demir, S. (2012). İşverenin İş Sağlığı ve Güvenliği Eğitimi Verme Yükümlülüğü Üzerine Bir İnceleme. Çalısma İliskileri Dergisi, 3(1), $23-47$.

Köse, Ş., Gül, S., Ersan, G., vd. (2011). Tepecik Eğitim ve Araştırma Hastanesinde Çalışan Temizlik Personellerinin Hastane İnfeksiyonları ve Temizliği Konusundaki Eğitiminin Değerlendirilmesi. Tepecike Ë̆itim Hastanesi Dergisi, 21 (2), 85-90.

Kurt, A. Ö., Harmanoğulları Üçeş, L., Ekinci, Ö. \& Ersöz, G. (2015). Bir Üniversite Hastanesi Temizlik Çalışanlarının Biyolojik Riskler Hakkındaki Bilgi, Tutum ve Davranışları. VIII. İşçi Sağlı̆̆ı ve İş Güvenliği Kongresi, 16-18 Nisan 2015, Adana. Poster Bildiri.

Özkılıç, Ö. (2005). İşçi Sağlığı ve İş Güvenliği Yönetim Sistemleri ve Risk Değerlendirme Metodolojileri, TISKK Yayınları, İstanbul: Ajans-Türk.

Kuruüzüm, Z., Elmalı, Z., Günay, S., Gündüz, Ş. \& Yapan, Z. (2008).Sağlık Çalışanlarında Kan ve Beden Sivılarıyla Oluşan Mesleksel Yaralanmalar: Bir Anket Çalışması. Mikrobiyoloji Bülteni, 42, 61-69.

Sarı N. D., Fincanc1, M., Soysal, F.H., Demirkıran, N.,Koyuncu, S.,Özgün, Ö. (2014). Delici Kesici Alet Yaralanmalarının Bildirim Sıklığı Neyin Göstergesi?. Med Bull Haseki; 52, 98-102.

Şafak, S. \& Erkal, S. (2011). Kurumlarda Ev İdaresi. Ankara: Detay Yayıncilı.

Terzi, Ö., Aker, S., Terzi, Ö., Sünter, A. T. \& Pekşen, Y. (2009). Hastane Temizlik Elemanlar1 ve Mesleki Enfeksiyon Riski: Bilgi ve Davranışlar Üzerine Bir Çalışma. İnönü Üniversitesi T⿰p Fakültesi Dergisi, 16(1), 7-12.

Toraman, A.R., Battal, F., Öztürk, K. \& Akcin, B. (2011). Sharps Injury Prevention for Hospital Workers. International Journal of Occupational Safety and Ergonomics (JOSE), 17(4), 455-461.

Uçkun, C. G., Yüksel, A., Demir, B. \& Yüksel, İ. (2013). Kurumsal İtibarın Artırılmasında İş Sağllğ̆ ve Güvenliği Kültürünün Rolü İle Meslek Yüksekokullarında Bulunan İş Güvenliği Uzmanlığ1 Programının Analizi. Elektronik. Mesleki Gelişim ve Araştırma Dergisi, 1(2), 57-67.

Yılmaz, V. \& Çelik, H. E. (2009). Lisrel ile Yapısal Eşitlik Modellemesi-I: Temel Kavramlar, Uygulamalar, Programlama. Ankara: Pegem Yayıncilik. 
Çiçek, B., \& Erkal, S. (2016). Hastanelerde kurum ev idaresi personeli perspektifinden iş sağllğ̆ ve güvenliği uygulamalarının ve güvenlik kültürüne ilişkin alg1 düzeylerinin belirlenmesi. Journal of Human Sciences, 13(3), 4416-4431. doi:10.14687/jhs.v13i3.3993

Yoldaş, Ö., Bulut, A., Ertürk, E., Çelik, D., Karakaşoğlu, Ü., Altındiş, M. (2014). Sağllk Çalışanlarında Enfekte Kan ve Vücut Sıvılarına Maruziyet Riskinin Belirlenmesi. Kocatepe T⿰p Dergisi, 15(3), 297-300.

Yorgun, S. \& Atasoy, A. (2013). Çalışan Sağllğı ve Güvenliği Kültürü Ölçeği Geliştirme Çalışması ve Uygulamaları. U. Beylik \& Ö. Öndere (Ed.), 3. Ulusal Sağlıkta Kalite ve Güvenlik Ödülleri Kitabı İçinde (s.17-32), Ankara.

Yüksel, Ö. (2003). İnsan Kaynakları Yönetimi. Ankara: Gazi Kitabevi.

Williamson, M. A., Feyer, A-M., Cairns, D. \& Biancotti, D. (1997). The Development of a Measure of Safety Climate: The Role of Safety Perceptions and Attitudes, Safety Science, 25(1-3), 1527.

6331 Sayılı İş Sağlığ1 ve Güvenliği Kanunu. (2012)

http://www.resmigazete.gov.tr/eskiler/2012/06/20120630-1.htm. Erişim Tarihi: 12.11.2015.

\section{Extended English Abstract}

Important developments have been experienced in service sector around the world in recent years. Thus, the understanding of health and safety at work has changed. While the problems of employees in the industry sector have been handled before, the service sector has been also included in the study area of health and safety at work. Although the area of health services with various departments and conducted by various professions has a significant place in the service sector, it is a risky area in terms of health and safety at work. Despite the fact that many studies were conducted in almost every field of health and safety at work and security culture in Turkey, these studies in the health sector were generally carried out in relation to medical personnel. However, health services includes many departments, requires teamwork and is conducted by different professions. The area of housekeeping, which is the leading one among supporting services at hospitals, has an important role. The aim of housekeeping is "to create a clean, bealthy, safe, organized and beautiful environment with the current facilities by benefiting from all resources owned at the bighest level." While achieving this goal, health and safety at work is one of the most important binding responsibilities. Therefore, this study was planned and conducted to identify the applications of health and safety at work and the perception levels related to security culture from the perspective of housekeeping personnel working at hospitals.

The population of the study consists of housekeeping personnel at 14 hospitals who accepted to participate in the study from all hospitals affiliated to the TR Ministry of Health and universities with more than 50 inpatient bed availability in Ankara city center apart from the hospitals specialized in certain fields, military hospitals and private hospitals within the boundaries of Ankara province $(\mathrm{N}=3510)$. The proportional sampling method was used in the determination of the number of personnel to participate in the study from each hospital that agreed to participate in it and the study was carried out with 400 housekeeping personnel.

A questionnaire form was prepared to collect the data in the study. The questionnaire form prepared was created as the first part including the personal information of the participants, second part measuring information related to health and safety at work, third part including the 'Safety Culture Scale' created by benefiting from the studies of Demirbilek (2005) and Demirbilek and Çakır (2008) and fourth part including the 'Employee Health and Safety Culture Scale' prepared by Yorgun and Atasoy (2013).

According to the results of the study, males $(52,0 \%)$ and those in the age group of 36-40 years $(23,5 \%)$ are leading among the personnel. While $34,4 \%$ of the housekeeping personnel have a primary school and lower level of education, 33,0\% have a high school and higher level of 
Çiçek, B., \& Erkal, S. (2016). Hastanelerde kurum ev idaresi personeli perspektifinden iş sağllğ̆ ve güvenliği uygulamalarının ve güvenlik kültürüne ilişkin alg1 düzeylerinin belirlenmesi. Journal of Human Sciences, 13(3), 4416-4431. doi:10.14687/jhs.v13i3.3993

education, 32,6\% are secondary school graduates and 77,5\% of the personnel are married. The personnel whose total service period $(36,0 \%)$ and service period at the hospital that he/she works at $(37,8 \%)$ are between $1-5$ years take the first place.

The housekeeping personnel who have received education in the field of "health and safety at work" comes first among the personnel almost all of which have received in-service training. It was identified that $10,3 \%$ of the personnel participating in the study had experienced occupational accidents. It was stated that $53,8 \%$ of the housekeeping personnel who had experienced occupational accidents had these accidents while 'collecting waste', 17,9\% had accidents while 'mopping', 15,4\% had accidents while 'carrying things', 12,8\% had accidents while 'using cleaning equipment', 5,1\% had accidents while 'cleaning the toilets' and 'wiping the windows' at equal rates. When the types of the accidents experienced by those who had had occupational accidents were examined, it was concluded that while the personnel 'exposed to sharp object injuries' took the first place with $63,4 \%$, it was followed by the personnel who had accidents due to 'falling' with $34,1 \%$, 'burns and scalds' with 7,3\%, and 'electric shock' with 4,9\%.

When the reason of occupational accidents was asked to the housekeeping personnel who had experienced them, $63,9 \%$ of the individuals stated that the accidents resulted from the 'unsafe behavior of the personnel' and $36,1 \%$ of the personnel said the accidents resulted from the 'unsafe working environment'.

While a statistically significant difference $(p<0,05)$ was found between the perception levels related to the 'Safety Culture' and 'Employee Health and Safety Culture' of the housekeeping personnel and the opinions of the personnel on the state of attaching importance to the applications related to health and safety at work by the hospital administration, the condition of receiving education on the use and maintenance of the equipment, accident protection and the use of cleaning products, there was no statistically significant difference $(p>0,05)$ between gender, age, total service period, education level, marital status, service period at the hospital of employment, the condition of experiencing occupational accidents at the hospital of employment, the reason of the accident experienced, general opinions related to the reasons of occupational accidents, cleaning methods, the condition of receiving education on infection control, sanitation and personal hygiene.

It was concluded from our study that the accidents experienced by the housekeeping personnel were 'preventive accidents'. Thus, including the subjects of health and safety at work in orientation training provided during personnel recruitment, employing the personnel in the positions suitable for his/her talent and not letting the personnel do other works not included in the job description, informing the personnel about the use of the protective equipment fully and completely when it is considered that risks and dangers increase while collecting, carrying and removing medical wastes and ensuring that they use the equipment, informing the management when unsafe working environment conditions arise during work performed by the personnel, creating a healthy and safe working environment, the cooperation of the top management and the personnel to achieve the purpose of all the arrangements performed/to be performed by the top management and trainings provided and ensuring that the personnel continuously participate in this cooperation are required to prevent occupational accidents, to adopt safe behaviors, to create health and safety at work and security culture at hospitals in a more effective way and to ensure its continuity. 